\title{
Decision Support System for Managing Educational Capacity Utilization
}

\author{
Svetlana Mansmann and Marc H. Scholl
}

\begin{abstract}
Decision-making in the field of academic planning involves extensive analysis of large data volumes originating from multiple systems. With the many new technology application areas evolving from the domain of electrical engineering, computer engineering, and computer science, deans and department chairs must ensure that new specializations and programs are adequately supported. Academic workload management is concerned with distributing teaching resources to support the university's educational framework adequately (faculties, degrees, courses, admission policies, teaching workload, etc.).

This work presents a methodology for assessing educational capacity and planning its distribution and utilization, implemented as a decision support system allowing simulation and evaluation of various proposals and scenarios. The system integrates input data from relevant sources into an autonomous data warehouse. Graphical client front-end ensures adequate output presentation to the decision-makers by revealing significant details and dependencies in the data.

Applying the system as an "on-the-fly" decision-support utility by the policy-makers leads to significant acceleration of planning procedures, deepens the insight into the data and the underlying methodology, and, consequently, provides for more efficient academic administration.
\end{abstract}

Index Terms-Academic decision support system, admission policy, curriculum planning, educational capacity.

\section{INTRODUCTION}

A CADEMIC resource planning is a highly complex administrative procedure based on extensive analysis of large volumes of data related to the educational framework, such as teaching resources, offered degrees, course structure and curricula, enrollment and retention, etc. Unfortunately, the prevailing state of the art of academic decision-making still has the form of an argumentative pie cutting barely backed up by solid quantitative analysis. However, the emergence of advanced information technologies has altered the operational environment of universities, offering them an opportunity to move on towards more systematic and efficient management of their assets. For example, practically the whole issue of IEEE TRANSACTIONS ON EDUCATION in late 2003 was dedicated to visions on electrical computer engineering (ECE) education in the future [1].

The authors are with the Department of Computer and Information Science, University of Konstanz, 78457 Konstanz, Germany (e-mail: Svetlana. Mansmann@uni-konstanz.de; Marc.Scholl@uni-konstanz.de).
Faculties are confronted with the necessity to reengineer the curricula of the offered study programs periodically or even design new curricula to keep pace with rapidly changing educational requirements. Within the United States and across Europe, the most recent annual meetings of department chairs of Electrical and Computer Engineering have focused almost exclusively on 1) meeting the need of evolving technologies that are either effecting changes in curricula or requiring the development of new curricula and 2) obtaining the resources for satisfying new curricula needs.

\section{A. Background}

The research presented here was inspired by the evolving reforms of the higher education system in Germany aimed at improving the performance of public universities in changing economic conditions. In 1998 and 2002, the federal government issued comprehensive amendments to the Framework Act for Higher Education [2], aimed at "preparing institutions of higher education for the new demands based on globalization, internationalization and competition" [3]. The core component of the reform-prompt and consequent conversion to internationally recognized Bachelor/Master degree system-has confronted universities with the challenge of reengineering their entire structures and adopting a fully new mode of operation. A detailed report on the progress and implications of implementing degree conversion in Germany and all over Europe as a part of the Bologna process may be found in [4].

Inapplicability of many of the existing policies and control instruments in the transformed operational environment has given rise to "hot" debates in legislative and academic circles. An example of such "outdated" policy is the heavily criticized student admission law in Germany. With minor modifications since the introduction in 1972, this law enforces a supply-oriented approach, based on maximum intake capacity, which has to be fully utilized given appropriate demand, thus adhering to the minimum standards of staff supervision for students and disabling university-specific variations [5]. The underlying computational model trades off accuracy and correctness for simplicity and rapid application with minimum software support. The University of Konstanz, Konstanz, Germany, responded to the call for reforms by proposing a pilot project on designing a flexible, demand-oriented admission policy model with its subsequent implementation as a Decision Support System (DSS). This work presents the outcomes of this project.

\section{B. Objectives}

The existing legal routines for quantifying the educational capacities of German universities serve merely for reporting on 
the usage of public funding and are perceived by the management as a bothersome formality. The goal of the new project was to propose a more comprehensive framework for assessing the university's resources in form of a DSS for academic policy makers. Major tasks of the systems were defined as follows.

1) Relevant input data has to be extracted from heterogeneous sources, brought into a consistent state and integrated into a single repository to provide a data basis for querying and computations.

2) A sound computational model for measuring the educational capacity and its utilization has to be designed. The model will account for frequent unavailability of parts of the input statistics by supporting different precision levels.

3) The proposed concept, as well as alternative approaches, is to be implemented in a user-friendly interface. Apart from standard computations and report generation, the system supports specification of user-defined simulation scenarios that may be used for testing various policy proposals and studying their implications. Decision-making process is supported primarily by means of intelligent presentation of the retrieved or computed data and by providing options for its explorative analysis. Focusing on the exploration rather than on generating prefabricated solutions has the advantage of ensuring the model's adaptability and applicability for a wide range of problems.

To keep pace with the requirements of the increasingly competitive environment, universities are forced to revise their curricula systematically, reallocate resources, introduce new course types or methods of teaching, or otherwise adapt to changing conditions. A minor adjustment in a course curriculum may cause significant shifts in the utilization of academic resources. Consider a worldwide emerging trend of setting up interdisciplinary study programs. Unlike with "classical" subjects, supervised by a single department for the most part, the responsibility for multisubject degrees is shared by all involved departments. Planning of interdisciplinary curricula infrastructure is barely manageable without an accurate approach for evaluating the available resources, especially if the funding leeway for supporting additional expenses is rather limited. The proposed model helps answer a wide range of queries about the actual utilization of the university's capacities, gain deeper insight into the academic processes, and carefully plan new strategies and means for their achievement.

\section{Related Work}

From the early days of information systems administrative academic processes, such as effective resource distribution, teaching personnel management, automation of student admission and registration, student performance, retention and dismiss, to name the major ones, have been among the "hottest" educational issues. First attempts to implement simulation models for handling educational resource management go back to the 1960s [6] with renewed enthusiasm in the 1990s apparently encouraged by the overall advancement of information technology.

In the 1980s, the academic decision theory focused mainly on formulating the general principles and approaches of the model-based DSS for academic environments [7], [8]. Various
TABLE I

CHARACTRISTICS OF THE CURRICULAR ENVIRONMENT

\begin{tabular}{l|l|}
\hline $\begin{array}{l}\text { Governance } \\
\text { Autonomy }\end{array}$ & $\begin{array}{l}\text { state authorization by federal states, national } \\
\text { curricular frameworks } \\
\text { limited to disciplinary profiling }\end{array}$ \\
\hline $\begin{array}{l}\text { Degree structure } \\
\text { one-cycle (traditional) gradually replaced by two- } \\
\text { cycle } \\
\text { flexible, low degree of organization }\end{array}$ \\
\hline $\begin{array}{l}\text { Curricula } \\
\text { detudent self- }\end{array}$ & high degree of freedom, individual curriculum \\
\hline $\begin{array}{l}\text { Interdisciplinarity } \\
\text { Internationalization }\end{array}$ & prequent, mostly as small portions of curriculum \\
\hline Access entitlement & secondary school certificate \\
\hline Length of study & de facto considerably exceeding de jure \\
\hline Funding & staff funded from the state budget \\
\hline Fees & no or moderate ( $\varepsilon 1000$ per year) \\
\hline
\end{tabular}

academic DSSs were proposed for handling problems, such as resource allocation [9]-[12], performance assessment [13], workload management [14], course scheduling [15], admission policy [16], advising [17], student profile evolution [18], and strategic planning [19]. More recent attempts circle around the data warehouse approach, in which the data integrated from decentralized applications is analyzed for solving complex administrative problems [20].

The contribution of the paper is twofold: 1) to propose the methodology for assessing the educational capacity, and 2) to implement the proposed approach in a DSS. The paper is structured as follows. Section II introduces the university data model and the characteristics of the underlying academic environment. The methodology of measuring the educational capacity is presented in Section III. Section IV outlines the implementation issues. Experiments of applying the proposed framework for solving capacity-related problems are described in Section V. Summary of the contribution and proposals for future work conclude the paper.

\section{MODELING THE EDUCATIONAL INFRASTRUCTURE OF A UNIVERSITY}

This section introduces the conceptual elements of the framework, such as actors, constraints, preferences, and assumptions. As mentioned in the introduction, the motivation for this work was to substitute the outdated formal routines for determining the educational capacity in terms of the number of students the university is able to accommodate under the specified constraints.

The curricular environment of the higher education system in Germany is summarized in Table I (a more detailed description may be found in [4]). The model is based on the assumption, that the "bottle-neck" resource of the educational capacity is the teaching staff. From experience, staff availability is by far the strongest constraint, expensive and hardly adjustable in the short-term compared to other resources involved, such as facilities, funding, etc.

Universities typically have a hierarchical structure consisting of faculties, degrees, and courses. Faculties, or departments, are 
the basic administrative units, each responsible for normally a single scientific discipline in terms of offering study programs and courses related to those programs. Multidisciplinary faculties, in case their disciplines were grouped merely for administrative reasons, are further subdivided into units to process each discipline separately. Considering both the administrative (faculties) and the scientific (units) decompositions enables distinguishing between interfaculty and truly interdisciplinary relationships.

Academic processes may be considered in terms of educational supply and demand relationships, with faculties as suppliers of educational services and students as their consumers. Obviously, university's resources are utilized fully if the per-faculty supply corresponds to its demand. An observation, that the responsibility for managing the curriculum, allocating teaching resources, and supervising enrolled students is carried out at the faculty level, turns faculties (units) into the main actors in the process of resource allocation. Therefore, the concept of educational supply and demand can be further substantiated on a per-faculty basis. Most curricular activities, such as lectures, tutorials, and seminars (courses), span one semester or can be mapped accordingly, so that the semester appears to be an appropriate time frame unit for resource utilization analysis.

\section{A. Educational Supply}

Educational supply measures the available teaching capacities as the volume of services the faculty's staff provides to students. Teaching resources are classified into position groups (e.g., professor, research assistant, etc.) with a specific teaching load assigned to each group by respective legislation. Teaching load defines the number of academic hours per week, denoted semester periods per week (SPW), to be invested in teaching. Thereby, the potential supply results from the total amount of available SPW while a particular instance of the supply consists of the courses actually offered by the staff in the specified period. Fig. 1 visualizes the above supply concept using the example of a two-disciplinary faculty.

\section{B. Educational Demand}

Educational demand describes the consumption of the faculty's academic services by the students who attend courses according to their respective curricula.

Faculties are responsible for study programs in their respective scientific discipline and, as such, supervise the students enrolled. Each study program is characterized by a subject and a degree. In case of composite degrees each major and minor subject has to be processed separately since they normally have different supervising faculties. Yet another case is an increasingly popular class of interdisciplinary programs whose very subjects are composite (e.g., bioinformatics). Consequently, such programs are supervised by more than a single faculty. Fig. 2 shows the composition of the demand at the example of two faculties.

\section{Cross-Faculty Relationships}

So far both the supply and the demand have been presented as having prevailing hierarchical structures (most faculty's subtrees do not overlap). In case of strict hierarchy, the faculties

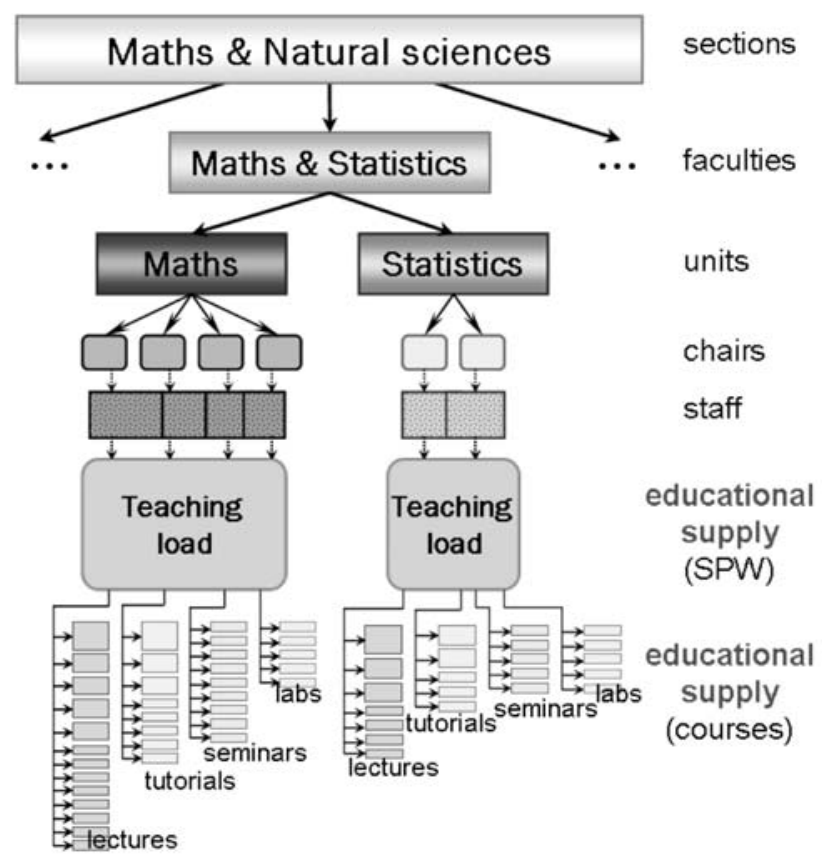

Fig. 1. Educational supply of a faculty.

manage exclusively their own available resources and supervised study programs. However, in reality, diverse cross-faculty dependencies exist on the part of both the supply and especially the demand. These intensive interrelations make isolated per-faculty optimization of capacity utilization unfeasible.

Major interdisciplinary issues and cross-faculty interactions arise at the following levels.

- Courses: Some courses with complex subjects are offered as a joint effort of teaching staff belonging to different faculties.

- Study programs: Study programs with interdisciplinary subjects enjoy increasing popularity. Multiple faculties, each responsible for its part of the curriculum, jointly supervise such programs. In Fig. 2, Life Sciences presents an example of a bidisciplinary program, supervised by faculties Biology and Chemistry.

- Degrees: Those degrees with subdivision into major/minor subjects (e.g., teacher's education degree) frequently encourage a combination of nonrelated subjects. Students enrolled in such degrees are registered within multiple faculties.

- Curricula: Curricula of most study programs contain blocks of courses offered by nonsupervising faculties, thus declaring their dependency on "imported" services.

Examples of the cross-faculty interactions at all levels, defined above, are presented in Fig. 3.

Cross-faculty teaching services can be modeled as exportsimports relationships of the faculties. From the viewpoint of a single faculty, assessment of its expected exports volume is indispensable since nonzero exports result in reduced capacity for servicing one's own programs. The next section describes the methodology for measuring educational supply and demand. 


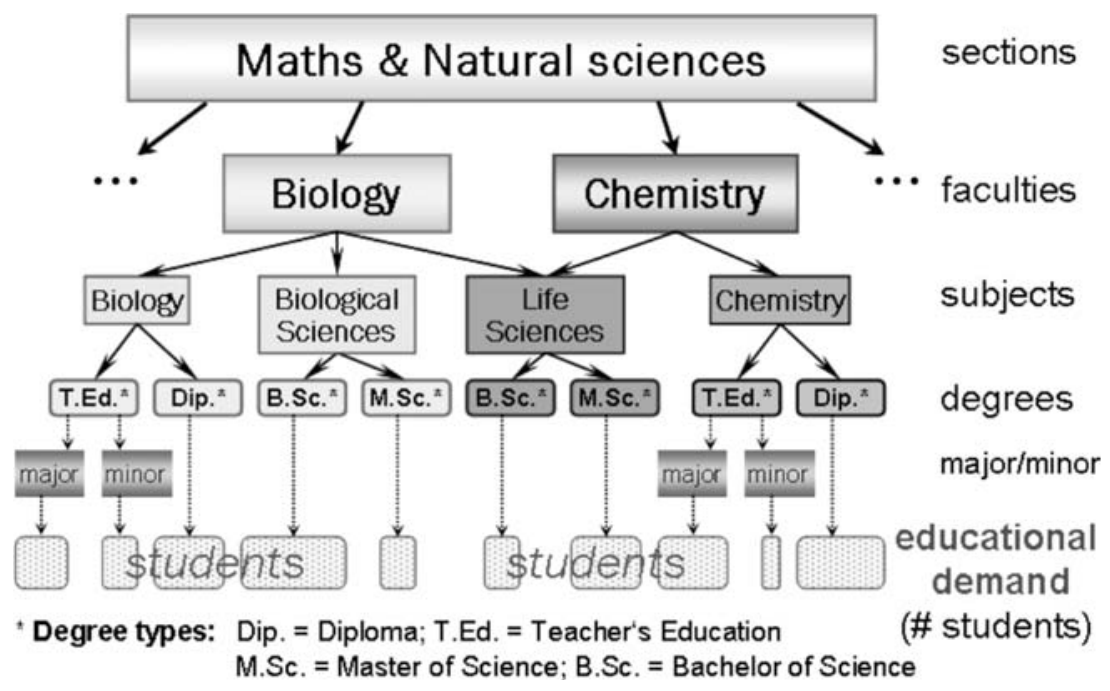

Fig. 2. Educational demand of a faculty.

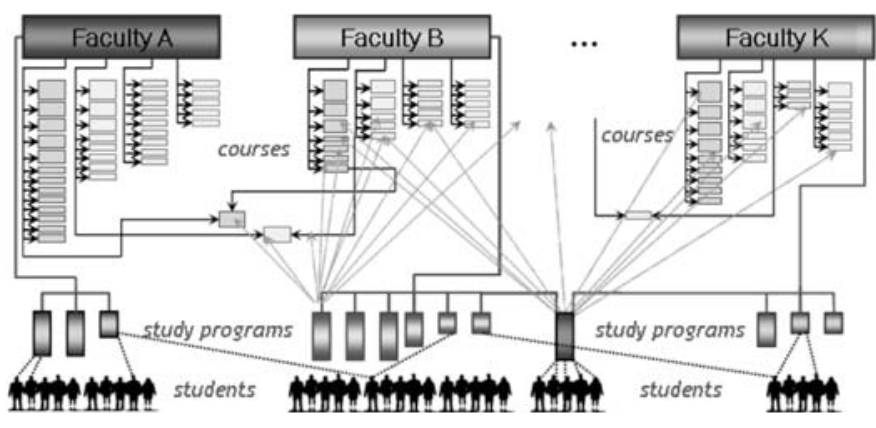

Fig. 3. Mapping cross-faculty dependencies (simplified fragment).

\section{Methodology}

As presented is Section II, the academic capacity utilization is all about providing and consuming curricular activities. The overall educational capacity is the total of the capacities of all offered courses. Each course is characterized by the volume measured in SPW and the support relation limiting the number of course participants. Additionally, course types can be weighted differently depending on the preparation-intensiveness on behalf of the teaching staff. Therefore, the teacher-hours-per-student cost of some course $C$ of type $T$ with support relation $N$, called the course's curricular value $(C V)$, can be estimated as follows:

$$
\mathrm{CV}_{C}=\frac{\mathrm{SPW}_{C} \times \text { weight }_{T}}{N_{C}} .
$$

Curricular value of some particular degree is thus the total of the $\mathrm{CVs}$ of all the courses specified in the respective curriculum, representing the necessary number of teacher periods per-student necessary for completing that degree. Table II shows an example of estimating the CV from the degree's curriculum.

Summing up the course CVs grouped by the servicing faculty (rows shaded with the same intensity in Table II) in the
TABLE II

Curricular VAlue of A StUdy Program (Fragment)

\begin{tabular}{|c|c|c|c|c|c|}
\hline semester & Course title & SWS & $\begin{array}{l}\text { support } \\
\text { relation }\end{array}$ & $\begin{array}{c}\text { offered by } \\
\text { faculty }\end{array}$ & CV \\
\hline \multirow{4}{*}{$1^{\text {st }}$} & Introduction into CS I & 6 & 150 & Comp. Sc. & 0.04 \\
\hline & Operating systems & 4 & 50 & Comp. Sc. & 0.08 \\
\hline & Maths for Programmer & 6 & 100 & Maths & 0.06 \\
\hline & \begin{tabular}{|c}
$\ldots$ \\
\end{tabular} & $\ldots$ & $\ldots$ & $\ldots$ & $\ldots$ \\
\hline \multirow{3}{*}{$2^{\text {nd }}$} & Algorithms\&Data Struct. & 6 & 100 & Comp. Sc. & 0.06 \\
\hline & Statistical Methods & 4 & 200 & Statistics & 0.02 \\
\hline & $\ldots$ & $\ldots$ & $\ldots$ & $\ldots$ & $\ldots$ \\
\hline \multirow{3}{*}{$3^{\text {rd }}$} & Information Systems & 6 & 100 & Comp. Sc. & 0.06 \\
\hline & Inform. Managemen & 6 & 100 & Comp. Sc. & 0.06 \\
\hline & $\begin{array}{c}\ldots \\
\end{array}$ & $\ldots$ & $\ldots$ & $\ldots$ & $\ldots$ \\
\hline & & $\ldots$ & & & \\
\hline \multirow{3}{*}{$6^{\text {th }}$} & Practical Assignment & 4 & 20 & Comp. Sc. & 0.5 \\
\hline & Project Management & 4 & 50 & Economics & 0.08 \\
\hline & Patent Law & 2 & 100 & Law & 0.02 \\
\hline \multicolumn{5}{|c|}{ Total Curricular Value (B.Sc. in Information Engineering) } & 3.85 \\
\hline
\end{tabular}

curriculum of degree $d$ yields the per-student demand within $d$ for each involved faculty. Such per-faculty portions in the total degree's CV are called faculty's curricular contributions $(C C)$ within a degree.

Intuitively, a convenient overview of all faculty/degree interactions is achieved by arranging the CCs into a matrix with faculties as columns and degrees (clustered by supervising faculty) as rows. Each cell $[d, F]$ thus describes faculty $F$ 's CC in degree $d$, as shown in Table III.

Deriving CCs from the curricula, however, may be rather aggravated if the latter are defined in a flexible manner, i.e., allowing students to select courses individually following some general selection rules. A possible solution is to synthesize a "representative" curriculum by combining formal curriculum definition with the analysis of the actual recent course attendance statistics.

For a single semester, the per-student demand value in any matrix cell $[d, F]$, divided by the length of degree $d$ in semesters, 
TABLE III

EXPORTS/IMPORTS RELATIONSHIPS WITHIN A UNIVERSITY (FRAGMENT OF FOUR FACULTIES)

\begin{tabular}{|c|c|c|c|c|c|c|c|}
\hline \multicolumn{2}{|c|}{ Degree / Faculty } & Maths & Comp. Sc. & Biology & Economy & & TOTAL \\
\hline \multirow{3}{*}{ 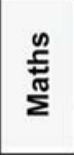 } & Maths, Dipl. & 1.80 & 0.30 & & 0.02 & \multirow{16}{*}{$\cdots$} & 3.20 \\
\hline & Maths, T.Ed./ major & 1.10 & 0.05 & & & & 2.45 \\
\hline & Maths, T.Ed./ minor & 0.55 & & & & & 1.82 \\
\hline \multirow{3}{*}{ 官 } & Inf. Eng., B.Sc. & 0.04 & 2.33 & & 0.03 & & 2.60 \\
\hline & Inf. Eng., M.Sc. & & 1.41 & & & & 1.85 \\
\hline & Comp. Sc., T.Ed./ minor & 0.04 & 1.80 & & & & 2.25 \\
\hline \multirow{3}{*}{$\begin{array}{l}\text { 흐 } \\
\frac{0}{0}\end{array}$} & Biology, Dipl. & 0.30 & & 5.11 & & & 6.44 \\
\hline & Biology, B.Sc. & 0.17 & 0.02 & 2.97 & & & 4.02 \\
\hline & Biology, M.Sc. & & & 1.85 & & & 2.25 \\
\hline \multirow{4}{*}{ 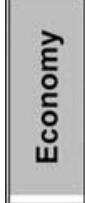 } & Economics, Dipl. & 0.92 & 0.02 & & 2.43 & & 3.40 \\
\hline & Economics, T.Ed./ major & 0.74 & 0.01 & & 2.11 & & 2.74 \\
\hline & Economics, B.Sc. & 0.80 & 0.04 & & 2.56 & & 3.05 \\
\hline & Economics, M.Sc. & 0.06 & & & 1.40 & & 1.74 \\
\hline \multirow{3}{*}{ 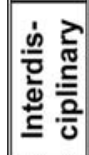 } & Inf. Management, B.Sc. & & 172 & & 2.12 & & 2.84 \\
\hline & Inf. Management, M.Sc. & & 0.90 & & 1.65 & & 1.50 \\
\hline & Life Sciences, B.Sc. & 0.05 & 0.02 & 2.78 & & & 4.55 \\
\hline
\end{tabular}

and multiplied with number of enrollments in $d$ in that semester, describes $d$ 's demand with respect to faculty $F$

$$
\operatorname{demand}_{d}^{F}=\frac{\mathrm{CC}_{d}^{F}}{\# \operatorname{semesters}_{d}} \times \# \text { enrollments }_{d} \text {. }
$$

Summarized vertically, the demand values produce the total required resources of faculty $F$. The ratio between $F$ 's total demand and the available teaching resources measured in SPW describes the faculty's teaching capacity utilization

$$
\text { CapUtilization }^{F}=\frac{\sum_{\text {all }} d^{\text {demand }^{F}} d}{\text { TeachingLoad }^{F}} \text {. }
$$

Further computational details and model parameters are omitted here because of the limited space. The introduced methodology can be applied for solving a wide range of problems related to planning academic capacity, such as

- determining the faculty's admission capacity for a specified degree setting (presented in [11]);

- locating the bottleneck faculty when modifying the degree structure;

- computing the necessary adjustment of teaching resources for supporting a certain scenario;

- checking whether there are any discrepancies between offered degrees and courses.

The tool can be extended by defining further types of reports and data views.

\section{A. Handling Missing Input Data}

Academic analysts are well familiar with the problem of incomplete or inconsistent input data. Since strategic planning has to be undertaken under any circumstances, a feasible solution is to include some robustness against missing input into the DSS by defining multiple precision levels, or granularities.

The highest confidence of the computation results is achieved if the input data is available at the finest granularity, i.e., the system disposes of the accurate enrollment/students statistics, full list of offered courses and their curricular values, course attendance statistics, clearly defined curriculum for each study program, available teaching resources, etc. Besides, all that data must be available for at least two years in order to "even out" short-term fluctuations.

So far, the system's operation at the highest precision has been hindered by the following deficiencies in the data.

- The online course schedules of many faculties are incomplete. Some courses are not announced online or are not sufficiently parameterized.

- Curricula are not defined as a fixed enumeration of courses to attend, but encourage individual choice of courses and only provide a set of guidelines and rules.

- Course attendance statistics is collected only by a subset of faculties.

The first two problems are overcome by introducing the course type precision level. Instead of referring to particular courses, the system considers only the course types. For instance, a classical undergraduate lecture type could be defined as follows: (Shown on the bottom of the next page.) 
TABLE IV

AGgRegated CURRICUluM OF A STUdy PROGRAM (FRAGMENT)

\begin{tabular}{|l|r|c|c|c|c|}
\hline \multicolumn{1}{|c|}{ Course type } & SwS & $\begin{array}{c}\text { support } \\
\text { relation }\end{array}$ & $\begin{array}{c}\text { offered by } \\
\text { faculty }\end{array}$ & occurrences & CV \\
\hline UndergraguateLecture & 6 & 200 & Comp. Sc. & 4 & 0.12 \\
\hline UndergraduateTutorial & 3 & 30 & Comp. Sc. & 10 & 1.0 \\
\hline AdvancedCourse & 4 & 50 & Comp. Sc. & 3 & 0.24 \\
\hline Practical Assignment & 4 & 20 & Comp. Sc. & 1 & 0.2 \\
\hline UndergraguateLecture & 6 & 200 & Maths & 2 & 0.06 \\
\hline SmallTutorial & 2 & 20 & Maths & 2 & 0.2 \\
\hline StandardLecture & 4 & 100 & Statistics & 1 & 0.04 \\
\hline AdvancedCourse & 4 & 50 & Economics & 1 & 0.08 \\
\hline StandardLecture & 4 & 100 & Law & 1 & 0.04 \\
\hline ... & $\ldots$ & $\ldots$ & $\ldots$ & & $\ldots$ \\
\hline
\end{tabular}

The defined occurring course types may then be used to translate rule-based curricula into the appropriate form of the list of courses, as shown in Table IV.

The model relies on course attendance statistics for "synthesizing" a representative curriculum from its formal definition. For instance, the definition may be "to have at least 12 SPW of advanced courses offered by any two of the following faculties ..." The statistics shows which of the courses are actually attended by what portions of the students, thus allowing the respective refinement of the curriculum. If such data is missing, the respective curricular contributions cannot be computed and are replaced by estimated values. This precision level is called the estimated curricular contribution level. Consistency of the estimates is ensured at the study program's level by forcing the values to sum up to the specified total curricular value of the program.

\section{IMPLEMENTATION}

The system has been implemented as a database-enabled Web-application as the multilayered client-server architecture best fulfills the requirements of a DSS with high availability and differentiated multiuser access. The computations are executed server-side using PHP (a programming language for embedding dynamic contents into Web sites) so that all a client needs for accessing the application is a Web browser and a network connection.

The major challenge is the preprocessing phase in which the entire input data has to be identified, collected, and integrated into a data warehouse. Depending on the types of the systems involved, the quality of the data (e.g., consistency, completeness, and format), and data protection constraints, this process may take up to several months. Fortunately, the model can operate on incomplete data for solving less complex tasks. In case of missing data, the user is prompted to specify a work around, for example, to use default values or assumptions, to compute the estimates by aggregating over historical data, or even to fill the gaps in the input manually.

Since ensuring complete and faultless automated data extraction and analysis is hardly feasible, expert knowledge of the users turns into a valuable asset and a significant contribution to the system's reliability and consistency.

In the simulation mode, the user is supplied with a copy of the input data, which can be manipulated to test the desired scenario. Both the underlying data and the reports from the simulation scenarios can be stored, reloaded, reprocessed, and shared among multiple users.

\section{APPLICATION AND EXPERIMENTS}

The graphical user interface was designed with the objective to encourage both strictly guided and freewheeling interaction modes. Most decision processes require combination of both approaches anyway. The expert would first use intuition to explore potentially relevant data and then apply analytical tools for assessing particular problem areas.

Guided interaction mode is implemented as an analytical toolbox with output report generation for a predefined set of academic problems and contains the following steps.

1) Select one of the predefined tasks from the list.

2) Select the type of report to generate.

3) Select the report options (precision level, aggregations, assumptions, error reporting, input inconsistency handling, etc.).

4) Adjust default values and assumptions.

5) Specify the input data requirements and options.

6) Adjust the input data to reflect the desired scenario.

7) Run the scenario and generate the output report(s).

8) Interactively explore the output (by "zooming" into data, aggregating, etc.).

9) Repeat steps 6-8 to find a satisfactory scenario or to collect the information required for a decision.

The presentation of the model is concluded by showing some fragments from the system's report generated when simulating the effects of the following scenario.

The Faculty of Biology and the Faculty of Computer Science are setting up a new interdisciplinary Master's degree in bioinformatics with the planned admission capacity of 30 enrollments per year. The task is to check whether this plan can be supported with the available teaching resources, and if not, to measure the necessary adjustment of the teaching load.

The screenshots in Fig. 4 present fragments from the generated reports, namely, the "before" (left) and "after" (right) state of each faculty's resource utilization as an enhanced bar chart. Faculties are listed in ascending order of their utilization ratios. The lower and the upper bounds of the specified tolerance interval and color intensity of the bars help identify unacceptably under- or overutilized faculties. In the initial state both faculties 


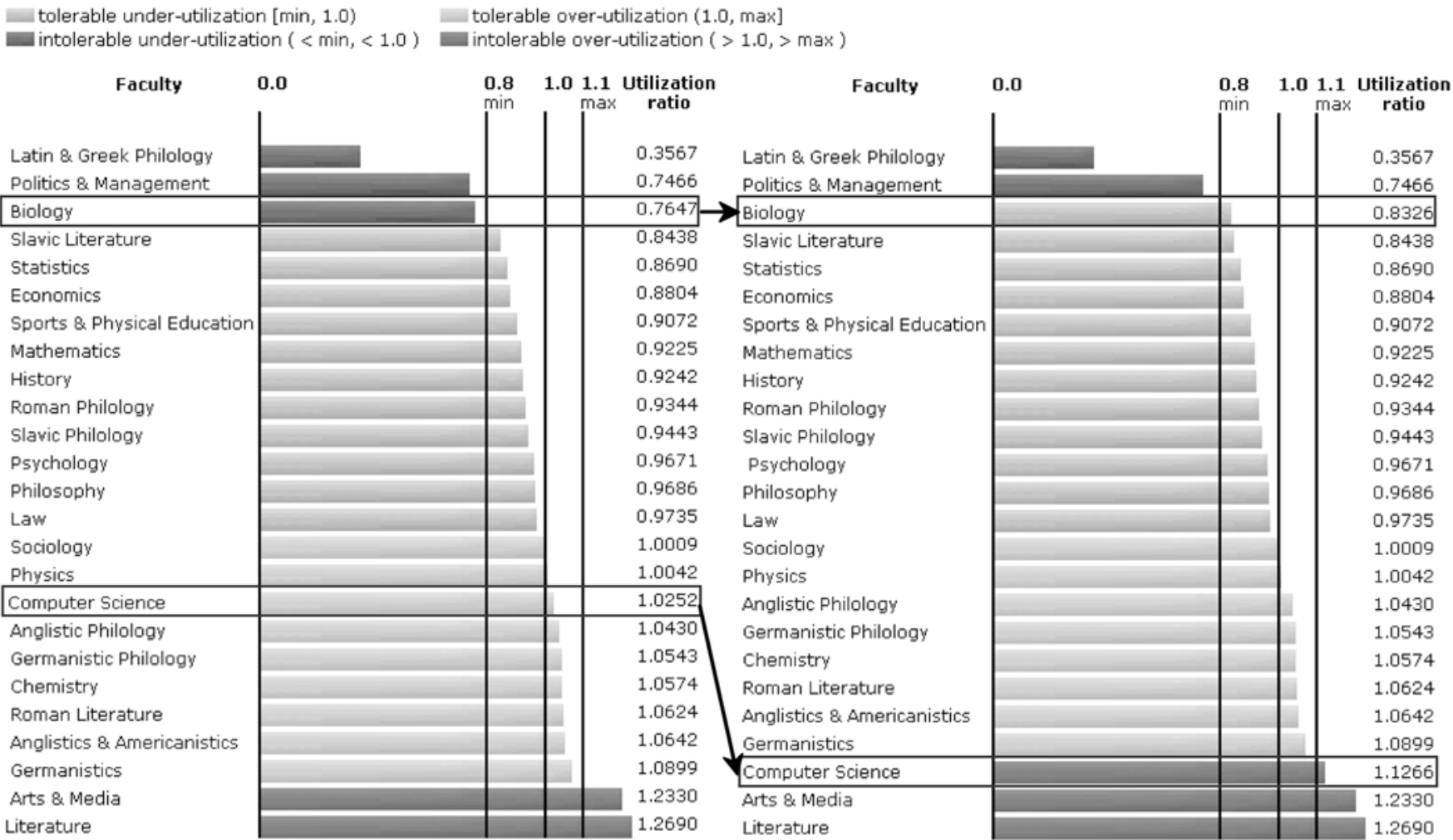

Fig. 4. Analyzing the resulting capacity utilization ratios of the faculties in a user-defined scenario. Left: initial state of the system. Right: the results of introducing an interdisciplinary study program Bioinformatics, M.Sc.

are indeed capable of allocating more resources while still remaining within the tolerance interval. However, the insertion of the new study program, its curriculum, and the expected number of enrollments leads to intolerable overutilization for the Faculty of Computer Science.

In the next step, the decision-maker retrieves the faculty profile report to study the details and come up with an adjustment policy. The report states that the Faculty of Computer Science is lacking at least 4 SPW in terms of teaching load, which corresponds to half of a full position, to come down to the boundary of 1.1. "Descent" to the course level helps to localize the courses with the "overflow" of participants-a tutorial and a seminar. The analyst's proposed solution may be use the acquired half position to "duplicate" the offer of those courses.

The scenario of adding an interdisciplinary degree cannot be supported by the existing supply-oriented approach in a straightforward manner. Interdisciplinary degrees are disallowed by imposing the constraint of a single supervisor faculty, however, they could be "artificially" assigned to one faculty (e.g., the one whose curricular contribution prevails) and entered as exports of the other supervising faculties.

The supply-oriented approach takes the available teaching resources as given and derives the maximum number of enrollments for each study program based on the faculty's teaching capacity, the cross-faculty contribution matrix, and the faculty's preferences about the portion of each supervised study program [4]. In the above scenario, the Faculty of Computer Science supervises a Bachelor's and a Master's degree in information engineering and a Master's degree in bioinformatics, with the desired enrollment portions of $0.55,0.2$, and 0.25 , respectively. The resulting annual enrollment numbers of 52, 19 , and 24 for the supervised study programs guarantee full capacity utilization of the faculty. Manipulation of the enrollment portions is the only way to change the resulting enrollment numbers. Decision-makers are generally not happy with such a solution since it disregards the multifaculty responsibility for interdisciplinary degrees.

Finally, an example of the aggregated views of the collected data from the university's overall report is presented in Fig. 5. The top pie chart shows the portions of supervised and nonsupervised degrees in the educational demand of a single faculty; whereas, the bottom pie chart is a decomposition of a degree's curricular value into curricular contributions of all involved faculties.

\section{CONCLUSION}

The work presented in this paper focuses on the problem of offering reliable decision support to the process of balancing educational demand and supply in universities. The academic structure is modeled as a supply-demand relationship between teaching resources and students. The methodology for assessing the educational capacity is based on correct and accurate mapping of cross-faculty dependencies into a university-wide curricular contribution matrix.

The model is implemented as a multiuser DSS for online construction and evaluation of academic scenarios. The system integrates data from heterogeneous university applications. Decision support functionality is realized as a reporting tool for 

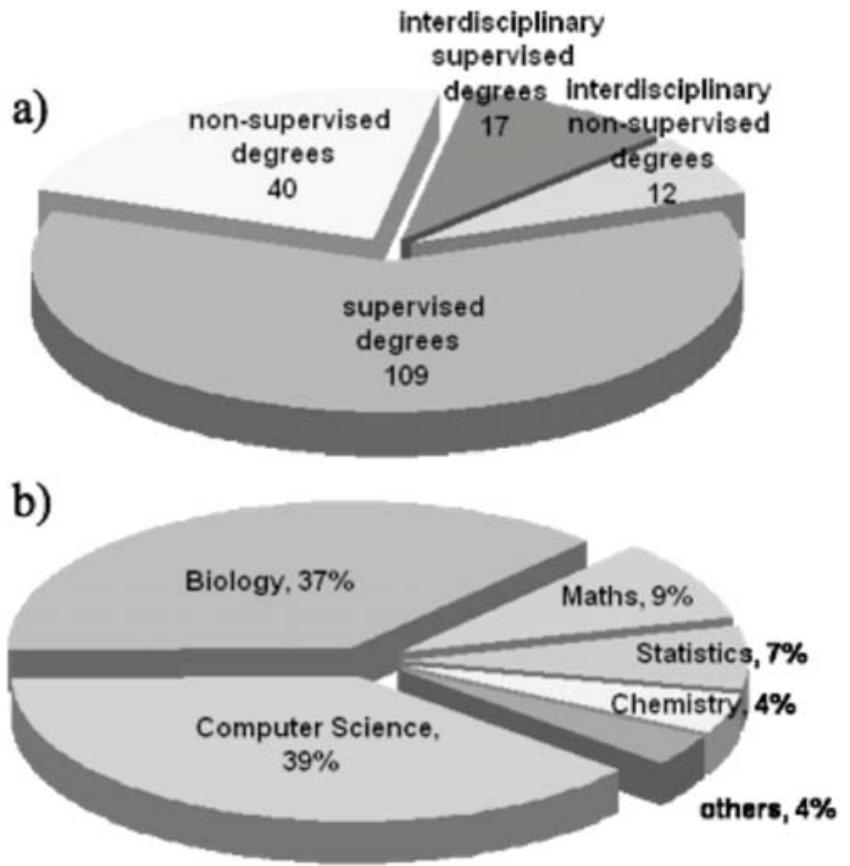

Fig. 5. Exploring the aggregated data. (a) Distribution of the faculty's educational demand. (b) Curricular contributions of the faculties in a degree.

solving particular capacity-related tasks by allowing users to query the data and navigate therein, to produce reports and visualizations, and explore the latter for gaining insight.

The future work on the project will be directed towards refining the methodology, improving the data integration routines, and enhancing the user interface to enable more intuitive and powerful interactive visual analysis and exploration of the accumulated data.

\section{REFERENCES}

[1] IEEE Trans Educ., vol. 46, no. 4, pp. 405-485, 2003.

[2] "Framework Act for Higher Education (Hochschulrahmengesetz, HRG)," Federal Ministry of Education and Research, Sept. 15, 2006 [Online]. Available: http://www.bmbf.de/pub/hrg_20050126_e.pdf

[3] "Higher Education Reform," Federal Ministry of Education and Research, Sept. 15, 2006 [Online]. Available: http://www.bmbf.de/en/ 655.php

[4] J. Witte, "Change of degrees and degrees of change: Comparing adaptations of European higher education systems in the context of the Bologna process," Ph D. dissertation, CHEPS, Universiteit Twente, Enschede, Netherlands, 2006.

[5] D. Müller-Böling, E. Mayer, A. MacLachlan, and J. Fedrowitz, Eds., "University in transition: Research mission-interdisciplinarity-governance," CHE Center for Higher Education Development, 1998, Gütersloh, Germany: Verlag Bertelsmann Stiftung.

[6] J. B. Levine, "Application of the CAMPUS simulation models to the major planning decisions of a large university," in Proc. 2nd Conf. Ap plications of Simulations, New York, 1968, pp. 317-328.

[7] S. K. Kassicieh and J. W. Nowak, "Decision support systems in academic planning: Important considerations and issues," Inf. Process. Manage., vol. 22, no. 5, pp. 395-403, 1986.

[8] E. Turban, J. C. Fisher, and S. Altman, "Decision Support systems in academic administration," J. Educ. Admin., vol. 26, no. 1, pp. 97-113, 1988.

[9] C. A. Casper and M. S. Henry, "Developing performance-oriented models for university resource allocation," Res. Higher Educ., vol. 42, no. 3, pp. 353-376, Jun. 2001
[10] N. Kwak and C. Lee, "A multicriteria decision-making approach to university resource allocations and information infrastructure planning,' Eur. J. Oper. Res., vol. 110, no. 2, pp. 234-242, Oct. 1998.

[11] S. Vinnik and M. H. Scholl, "UNICAP: Efficient decision support for academic resource and capacity management," in Proc. Int. Conf. E-Government: Towards Electronic Democracy (TCGOV), Bozen-Bolzano, Italy, 2005, pp. 235-246.

[12] L. S. Franz, S. M. Lee, and J. C. Van Horn, "An adaptive decision support system for academic resource planning," Decision Sciences, vol. 12, no. 2, pp. 276-293, 1981.

[13] D. Z. Deniz and I. Ersan, "Using an academic dss for student, course and program assessment," in Proc. Int. Conf. Engineering Education (ICEE), Oslo, Norway, 2001, pp. 6B8-12-6B8-17.

[14] D. Z. Deniz, M. Uyguroglu, and H. Yavuz, "Departmental workload administration using group forecasting in universities," in Proc. Int. Conf. Engineering Education (ICEE), Manchester, U.K., 2002 [Online]. Available: http://www.ineer.org/Events/ICEE2002/Proceedings/ Papers/Index/O013-O019/O016.pdf

[15] S. B. Deris, S. Omatu, H. Ohta, and P. A. B. D. Samat, "University timetabling by constraint-based reasoning: A case study," J. Oper. Res. Soc., vol. 48, no. 12, pp. 1178-1190, Dec. 1997.

[16] A. A. Elimam, "A decision support system for university admission policies," Eur. J. Oper. Res., vol. 50, no. 2, pp. 140-156, Jan. 1991.

[17] W. S. Murray and L. Le Blanc, "A decision support system for academic advising," in Proc. Association of Computer Machinery Symp. Applied Computing, Nashville, TN, 1995, pp. 22-26.

18] V. M. Borden, J. F. Dalphin, and L. Carson, "Simulating the effect of student profile changes on retention and graduation rates: A markov chain analysis," presented at the 38th Annu. Forum Association for Institutional Research, Minneapolis, MN, May 1998.

[19] Y. Barlas and V. G. Diker, "A dynamic simulation game (UNIGAME) for strategic university managements," Simulation \& Gaming, vol. 31 no. 3 , pp. 331-358, Sep. 2000

[20] J. Ingham, "Data Warehousing: A tool for the outcomes assessment process," IEEE Trans Educ., vol. 43, no. 2, pp. 132-136, May 2000

Svetlana Mansmann received the M.Sc. (Dipl.) degree in international economic relations from Belarusian State University, Minsk, Belarus, in 1999, and the M.Sc. degree in information engineering from the University of Konstanz, Konstanz, Germany, in 2003.

She is working towards the Ph.D. degree in computer science. She is currently a Research Assistant in the Databases and Information Systems Group at the University of Konstanz. Her previous research fields are decision support systems and e-Government. Her recent publications focus on data warehousing and business intelligence, multidimensional data modeling, and information visualization. Along with her supervisor, Marc H. Scholl, she received Best Paper Awards at the International Conference on Engineering and Computer Education in 2005, and the International Conference on Data Warehousing and Knowledge Discovery in 2006.

Ms. Mansmann has been an Associate Member of the Graduate College "Explorative Analysis and Visualization of Large Information Spaces" at the University of Konstanz since 2004

Marc H. Scholl received the M.Sc. (Dipl.-Inform.) and Ph.D. (Dr.-Ing.) degrees in computer science from the Technical University of Darmstadt, Darmstadt, Germany, in 1982 and 1988, respectively.

$\mathrm{He}$ is currently a Full Professor of Computer Science at the University of Konstanz, Konstanz, Germany. From 1998 to 2004, he served as Vice President of the University, responsible for the information infrastructure. His previous positions include an Associate Professorship at the University of Ulm, Germany (1992-1994) and an Assistant Professorship ("Oberassistent") at ETH Zurich, Switzerland (1989-1992). Current research topics include XML and databases, query processing and optimization, database management system architecture, data warehouse applications, and interfaces for decision support and e-Government applications.

Prof. Scholl is a member of the IEEE Computer Society, the Association for Computing Machinery (ACM), the ACM Special Interest Group on Management of Data (SIGMOD), the Extending Database Technology (EDBT) Association (currently EDBT President), the International Conference on Database Theory (ICDT) Council, and the German Computer Society (GI). 